\title{
E-VOTING AND NON-RESIDENT CITIZENS' VOTER TURNOUT: A QUASI-EXPERIMENT IN ECUADOR
}

\author{
Régis Dandoy ${ }^{1,2,3}$ and Sebastián Umpierrez de Reguero ${ }^{4,5,6}$ \\ ${ }^{1}$ Universidad San Francisco de Quito, Quito, Ecuador \\ ${ }^{2}$ Université Libre de Bruxelles, Brussels, Belgium \\ ${ }^{3}$ Waseda University, Tokyo, Japan \\ ${ }^{4}$ Leiden University, Leiden, The Netherlands \\ ${ }^{5}$ Diego Portales University, Santiago, Chile \\ ${ }^{6}$ European University Institute, Fiesole, Italy
}

\begin{abstract}
Over the last decades, e-voting has been used in a large number of countries and its impact on voter turnout has been closely scrutinized. Regardless, scholarly attention has largely focused on turnout in the domestic arena, and the link between e-voting and external voting have been scarcely explored. Based on a quasi-experimental design of the 2021 Ecuadorian elections, we investigate the effect of both on-site electronic voting and Internet voting on non-resident citizens' voter turnout. This paper shows that, while on-site electronic voting seems to have no significant impact on turnout, turnout of non-resident citizens using Internet voting significantly increased as compared to prior elections and to neighboring electoral districts.
\end{abstract}

\section{KEYWORDS}

E-voting, Internet Voting, Turnout, Ecuador, External Voting

\section{INTRODUCTION}

In preparation of the 2021 presidential, legislative and Andean elections in Ecuador, the electoral management body - the National Electoral Council - decided to run pilots regarding different voting modalities for Ecuadorian voters living abroad. These pilots consisted in organizing binding elections in three different electoral districts located abroad based a voting modality different that in-person voting in the polling stations hosted in consulate and diplomatic venues: postal voting, on-site electronic voting (direct-recording electronic or DRE voting) and Internet voting. In the form of a quasi-natural experiment, these pilots constituted a unique opportunity to investigate the impact on the voting modality on the decision of some voters to participate in elections.

Compared to the analysis of e-voting in the participation of non-resident voters, empirical studies analyzing the impact of e-voting on voter turnout in domestic electoral districts are relatively frequent. Yet, their conclusions diverge. On-site e-voting (DRE voting) leads to higher turnout in Japan (Tsukiyama, 2018) and Switzerland (Petitpas et al, 2020), to lower turnout in Belgium (Dandoy, 2014; Dejaeghere \& Vanhoutte, 2015) and India (Debnath et al, 2017), while other scholars find no statistically significant effect of DRE voting on turnout in Brazil (Fujiwara, 2015), in India (Desai \& Lee, 2019) and in the Netherlands (Allers \& Kooreman, 2009). Similarly, contributions on Internet voting leads to divergent findings as various scholars suggest that internet voting has no effect on domestic voter turnout in Estonia (Bochsler, 2010) and in Switzerland (Germann \& Serdült, 2017) while others find out that internet voting increases voter turnout in Brazil (Spada, Mellon, Peixoto, \& Sjoberg, 2016) and in Canada (Goodman \& Stokes, 2020).

Even if numerous scholars have already suggested the importance of Internet voting in long distance elections, notably for increasing electoral turnout since it facilitates the act of voting, turnout among non-resident voters has not been the focus of much research (Petitpas et al, 2020). Exceptions are to be found in the recent works of Fowler (2020) and Germann (2021), who found out that internet voting increased turnout - respectively - by 3 to $5 \%$ in the United States of America (West Virginia) and by 5\% in 
Switzerland. In the French case, Dandoy and Kernalegenn (2021) observed that Internet voter turnout among French non-residents is more likely to be higher in large and developed countries as well as in European countries.

The research objective of this short paper is to explore the impact of DRE voting and Internet voting on turnout for voters living abroad in an overlooked country case (Ecuador) at the occasion of the 2021 presidential, legislative and Andean elections and to contribute to the burgeoning literature on the consequences of different modalities of e-voting on voter's behavior. Based on the short literature review presented above, our hypothesis is that the voting modality has an impact on turnout: a higher turnout should be observed among non-resident Ecuadorians using Internet voting, while no significant difference in turnout should be observed among non-resident Ecuadorians using DRE voting.

In what follows, we present in a first section the characteristics of the Ecuadorian external voting system and we discuss the measurement of voter turnout. A second section analyses turnout figures in the two electoral districts where e-voting (DRE voting and internet voting) was used and compares then with previous elections, whereas considering gender and the type of elections. A third section compares turnout figures for four different types of voting modalities in the two analysed electoral districts as well as in neighbouring districts. This note concludes that while DRE voting seems to have no significant impact on turnout, Internet voting had a positive effect on turnout. Compared to districts using ballot box voting, overall turnout increased respectively by $13,09 \%$ and $12,12 \%$ in the district using Internet voting.

\section{E-VOTING AND TURNOUT IN THE 2021 ELECTIONS IN ECUADOR}

\subsection{External Voting in Ecuador}

External voting (i.e., voting from abroad or out-of-country voting) can be defined as the provisions and procedures that allow voters who are temporarily or permanently outside the country of citizenship to exercise their voting rights. Since 2006, Ecuador permits its non-resident nationals to participate in the presidential elections and these voting rights have been since 2008 enlarged to four other types of elections: legislative elections, in both a nation-wide district (the so-called 'national seats') and in three overseas districts the so-called 'territorial seats'; ${ }^{1}$ supra-national elections (i.e., for the Andean Parliament); elections for the Citizen's Council; and in referenda and popular consultations. These elections are often organised simultaneously, and turnout figures tend to be very similar across types of elections.

Although voting in Ecuador is compulsory ${ }^{2}$, active electoral rights of non-resident Ecuadorians are facultative. Overall, non-resident citizens' voter turnout is relatively high compared to other Latin American countries; still, akin eligibility rights. ${ }^{3}$ Non-resident citizens' voter turnout in Ecuador (from about $20 \%$ up to $60 \%$, depending on the type of election) is higher than in Argentina and Mexico, and very similar to Bolivia and Peru (Bermúdez et al, 2017; Burgess, 2018). Furthermore, voter registration is fairly easy - permanent and one-off - but the voting method have been somehow been restrictive until 2019. One the one hand, non-resident Ecuadorian must change their domicile once living abroad and thereafter, they can vote in national- and supranational-level elections any time they want. Over the last years, registration is not only channelled at consular offices by the electoral management body, but also online. Additionally, consular staff has often mobilised, including in rural areas, in the main destination countries of Ecuadorians (for instance in Italy, Spain or the USA) in order to facilitate their enrolment prior to each election (Ramírez, 2018). On the other, in-person voting was the only method for non-resident Ecuadorians to partake in homeland elections, and it was largely contingent upon the presence of consular offices. The combination of these electoral rules and consular practices increased the number of non-resident Ecuadorians inscribed to vote from abroad in an exponential manner (from 143.352 voters in 2006 to 410.145 in 2021). Yet, non-resident citizens' voter turnout has decreased over time (Umpierrez de Reguero \& Dandoy, 2020).

\footnotetext{
${ }^{1}$ Non-resident Ecuadorians can elect their six emigrant representatives in their national legislature, two in each overseas electoral district.

${ }^{2}$ Turnout in mainland Ecuador is often above $80 \%$. Despite the Covid-19 crisis, turnout for the 2021 elections reached $81 \%$.

${ }^{3}$ In Ecuador, such as in most Latin American countries, eligibility rely on both jus sanguinis and jus soli modes of citizenship acquisition.
} 
In this paper, we differentiate between two main operationalizations of turnout. First, the overall turnout measures the percentage of voters that participated in the elections based on the total number of registered voters in a district. Second, the effective turnout takes into account the invalid votes (i.e., the blank and null votes) in the calculation of turnout: it is measured as the number of valid votes divided by the total number of registered voters. This differentiated operationalization of the electoral participation into overall and effective turnout follows recent works on turnout (see for instance Barnes \& Rangel, 2018; Dandoy \& Kernalegenn, 2021). The use of voting machines instead of traditional paper ballots constitutes an effective method to reduce voter errors and uncounted ballots (Álvarez \& Hall, 2008) and Germann (2020) concluded that internet voting reduced the risk of voters making mistakes in Switzerland.

The analysis of effective turnout is particularly relevant in the case of Ecuadorian elections. Unlike in many other countries, Ecuadorian voters have the legal possibility to express a blank or invalid vote, independently on the chosen voting modality. There are no specific provisions for paper voting (i.e., the voter can leave his/her ballot empty in order to express a blank vote while the voter can indicate ' $n u l o$ ' or even make a large mark on the ballot in order to express a null vote). However, the e-voting system provides the voter with two additional options: two additional buttons appear on the screen - usually at the bottom of the list of parties or candidates - allowing the voter to express a blank or an invalid vote instead of a vote for a specific party or candidate.

Moreover, the share of invalid and/or blank vote is traditionally high in Ecuadorian elections - usually around $10 \%$ for the presidential elections and even higher in second-order elections. This is partly explained by the fact that voting is compulsory for large segments of the Ecuadorian voting population and that voters may express their discontent with this obligation by emitting a blank or an invalid vote. During the 2021 electoral campaign, several prominent political actors called voters to 'annul' their votes in order to protest against the fact that some parties and candidates were not allowed to participate in the elections. Altogether, these elements indicate the importance of distinguishing overall and effective turnout in our analyses.

\subsection{Voter Turnout Abroad: Differences Over Time}

The analyses presented in this short paper rely on official election results at the district level. To our knowledge, there have been no attempts to collect data at the individual level in the two districts using e-voting in the 2021 Ecuadorian elections. We are aware of the limitations of our findings since they are solely built on descriptive statistics. The small number of overseas districts does not allow for more in-depth quantitative analysis. Yet, given that male and female citizens vote separately, we are able to present results across gender for the different types of voting modalities.

We first turn to the observed differences in non-resident citizens' voter turnout in the 2021 presidential, legislative and Andean elections compared to previous elections for the two districts that adopted an e-voting modality (in the 2017 elections, these districts used paper-based voting). In the Buenos Aires district (DRE voting), 2.082 Ecuadorians were registered, whereas only 567 enrolled in the Phoenix district (Internet voting). This is a significant increase since previous elections were only 1.481 and 304 were registered respectively, meaning that many voters were potentially first-time voters. However, it is important to notice that the decision of electoral management body to run e-voting pilots in these districts was taken after the closing of the registration of Ecuadorians living abroad. This prevents the occurrence of two potential sample selection biases: non-resident Ecuadorians that would not have registered knowing that e-voting would be used in their electoral district, or that would have registered only in order to participate electronically to the elections.

Strikingly, we observe noteworthy differences between the two districts using different e-voting modalities. In the Buenos Aires district (DRE voting), overall turnout figures dropped by more than 10\% (see Table 1) compared to previous elections. Conversely, overall turnout increased by more than $11 \%$ in the Phoenix district where Internet voting was used, compared to previous elections. There are no significant differences depending on the type of elections as turnout figures are by definition fairly similar given that they occur on the same day.

These observations are verified when using an alternative measure of turnout that considers null and blank votes. Effective turnout dropped by almost $10 \%$ in the electoral district using DRE while it increased by almost $10 \%$ in the electoral district using Internet voting. Yet, the effect of e-voting on participation decision in both districts is slightly lower than for overall turnout as there were - on average - less blank and 
null votes in 2021 compared to previous elections. Since non-resident Ecuadorians had the opportunity to participate in three different elections ${ }^{4}$, we can also analyze the differentiated impact on e-voting on turnout for each type of elections. In the electoral district using DRE voting, the e-voting penalty is higher for the presidential and district-based legislative elections (reserved seats) and there are proportionally less blank and null votes in the legislative elections (national seats). In the electoral district using Internet voting, the benefits of e-voting in terms of political participation are particularly large in the presidential elections $(+10.97 \%)$ whereas they are relatively more modest for the legislative elections (reserved seats) with an effective turnout bonus of $+9.03 \%$.

Table 1. Average turnout in the 2017 and 2021 elections in Ecuador

\begin{tabular}{|c|c|c|c|c|c|c|}
\hline & \multicolumn{2}{|c|}{ Overall turnout (average) } & \multicolumn{4}{|c|}{ Effective turnout (average) } \\
\hline & $\begin{array}{c}2017 \\
\text { (Paper voting) }\end{array}$ & $\begin{array}{c}2021 \\
\text { (E-voting) }\end{array}$ & Difference & $\begin{array}{c}2017 \\
\text { (Paper voting) }\end{array}$ & $\begin{array}{c}2021 \\
\text { (E-voting) }\end{array}$ & Difference \\
\hline $\begin{array}{l}\text { Buenos Aires } \\
\text { (DRE voting) }\end{array}$ & $46.70 \%$ & $39.95 \%$ & $-10.75 \%$ & $41.90 \%$ & $31.96 \%$ & $-9.94 \%$ \\
\hline $\begin{array}{c}\text { Phoenix } \\
\text { (Internet voting) }\end{array}$ & $19.49 \%$ & $30.65 \%$ & $+11.05 \%$ & $18.43 \%$ & $28.35 \%$ & $+9.92 \%$ \\
\hline
\end{tabular}

We also replicated the analyses per gender as female voters in Ecuador traditionally tend to display higher turnout figures than male voters. Both measures of turnout drop significantly in the electoral district using DRE voting machines but its negative impact on overall turnout is slightly higher for female voters. Since the share of blank and null votes is higher for male voters, the negative impact of DRE voting on effective turnout is larger in the case of this group of voters $(-10.48 \%)$ compared to female voters $(-9.57 \%)$. In the electoral district using Internet voting, the positive impact on turnout strongly depends on the gender of the voter. On average, the measure of overall turnout increases by $8.31 \%$ among male voters and no less than $13.80 \%$ among female voters. In other words, the Internet voting bonus in overall turnout is higher for female than for male voters. This differentiated impact loses some its strength when looking at effective turnout, even if we still observe relevant differences between male voters $(+8.70 \%)$ and female voters $(+11.14 \%)$.

\subsection{Voter Turnout Abroad: Differences Across Types of Ballots}

We also compared our measures of overall and effective turnout across four different types of ballots (see Table 2): paper ballots emitted in-person in the consulate building (i.e., ballot box votes), postal paper ballots (i.e., postal votes), electronic ballots filled in-person in the consulate building (i.e., DRE votes) and internet ballots (i.e., Internet votes). We included in our analyses the three electoral districts where pilots have been running by the Ecuadorian electoral management body and their average figures for the two geographically closest electoral districts using ballot box voting. This geographical proximity allows us to limit the socio-demographic variation of the characteristics of the electorate in various abroad districts. ${ }^{5}$ But more importantly, it allows us to control for similar trends observe in the neighboring districts and for the potentially differentiated impact of the Covid-19 situation on voter mobilization. There are indeed relevant geographical variations of turnout among districts that relied on ballot box voting: turnout is significantly higher in South American than in North American electoral districts.

Table 2. Different types of ballots used for the 2021 Ecuadorian elections

\begin{tabular}{|c|c|c|}
\hline & Consulate & Distance \\
\hline Paper & $\begin{array}{l}\text { Ballot box } \\
\text { voting }\end{array}$ & Postal voting \\
\hline Electronic & DRE voting & Internet voting \\
\hline
\end{tabular}

\footnotetext{
${ }^{4}$ Voters were given four different ballots: one for the presidential elections, two for the legislative elections (one for the national seats, one for the reserved seats for Ecuadorian living abroad) and one for the Andean parliamentary elections.

${ }^{5}$ The nine analyzed electoral districts are: Buenos Aires (DRE voting), Montevideo and Santiago (ballot box voting); Phoenix (Internet voting), Houston and Los Angeles (ballot box voting); and Ottawa (postal voting), Montreal and Toronto (ballot box voting).
} 
We observed that the introduction of alternative modalities of voting affected turnout figures compared to neighboring districts (see Graphs 1 and 2). In the electoral district where DRE voting was used, the average overall turnout for the three different elections (presidential and Andean ${ }^{6}$ elections as well as the two ballots for the legislative elections) is slightly lower than in neighboring districts using ballot box voting while the average effective turnout is slightly higher. Differences are within the margin of standard errors, meaning that we do not observe differences in turnout between districts using DRE voting and districts using ballot box voting. This finding also helps us relative the observed decline of turnout declined compared to previous elections as this trend is similar in neighboring South American electoral districts. Regarding gender, the average negative difference in overall turnout is larger among male voters, while the average positive difference in effective turnout is larger among female voters.

Contrary to DRE voting, the impact of Internet voting on turnout is significantly more important and positive. On average, overall turnout is higher by $13 \%$ in the electoral district using Internet voting compared to neighboring districts using ballot box voting. Effective turnout is similarly higher $(+12 \%)$ in the electoral district using Internet voting compared to neighboring districts using ballot box voting. Therefore, we can affirm that Internet voting seems to have a significant and positive impact on turnout in the US electoral districts. Regarding gender, average differences in both overall and effective turnout indicate that Internet voting has a larger positive impact on women than on men. More specifically, there are proportionally more blank and null votes in the group of male voters compared to neighboring districts using ballot box voting.

Finally, postal voting has a similar positive impact on turnout as the electoral district implementing this voting modality displays an overall and effective turnout more than $20 \%$ superior compared to turnout in neighboring districts based on ballot box voting. There are no significant differences regarding gender in both types of turnout measurement.

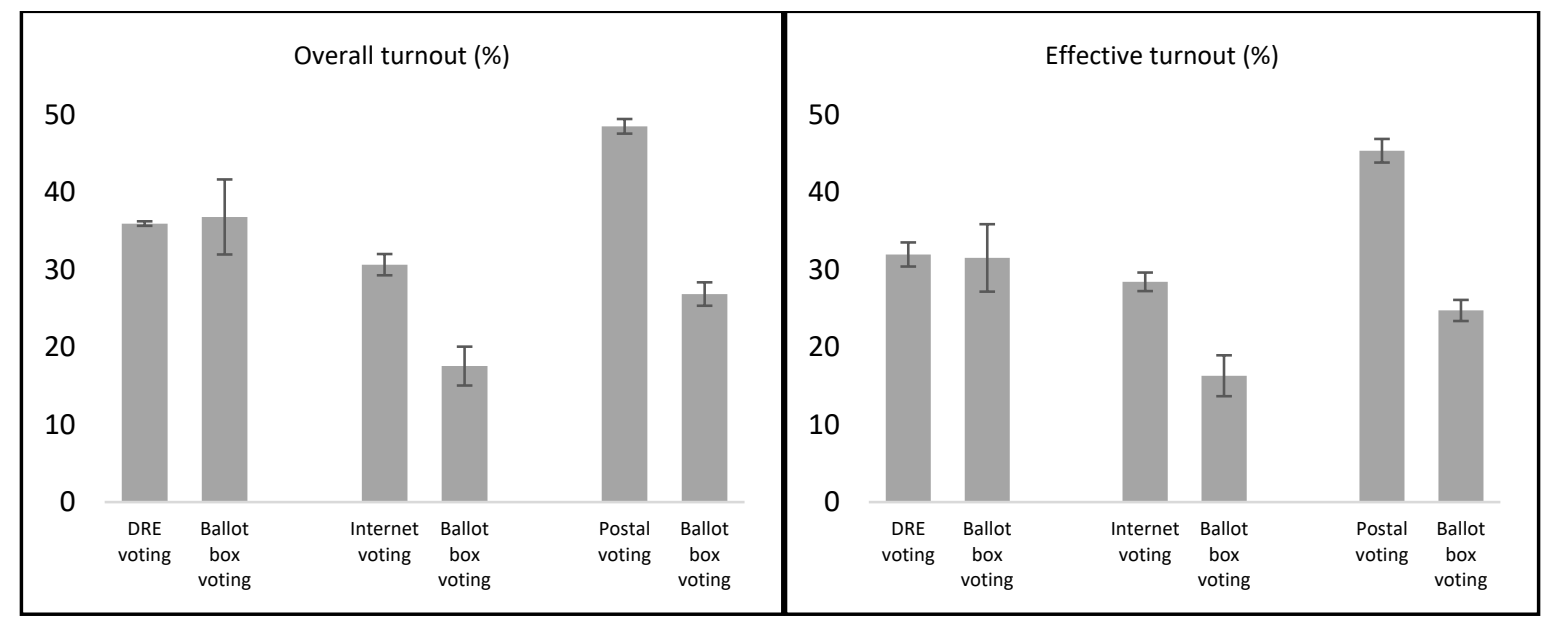

Graphics 1 and 2. Average turnout per voting modality in the 2021 elections in Ecuador

\section{CONCLUSION}

The elections of 7 February 2021 in Ecuador constituted a quasi-natural experiment as - for the first time in the political history of this country - two electoral districts abroad used e-voting (one relied on DRE voting while the other relied on Internet voting) while neighboring districts kept using on-site paper voting. This situation allowed us to evaluate the impact of these different voting modalities on turnout in abroad district. Even if the gathered data may appear modest (overall it concerns only a few thousand voters), our two main findings seem in synchrony with the blooming literature linking technology and external voting. Based on the burgeoning literature on turnout among non-resident voters, our hypothesis was that the voting modality had

${ }^{6}$ Given the late sending of the ballot papers in abroad districts, voters from the Ottawa district could not vote for the Andean parliament. As a proxy for these elections are calculated as the average figures of the two other plurinominal elections (the two ballots for the legislative elections). 
an impact on turnout: we expected to observe a higher turnout among non-resident Ecuadorians using Internet voting, while we expected no significant difference in turnout among non-resident Ecuadorians using DRE voting.

Based on descriptive statistics, the findings presented in this short paper confirm our hypotheses. First, we observed that DRE voting seems to have no significant impact on non-resident citizens' voter turnout, even this measure drops compared to previous elections (2017). The effect of DRE voting is negative when evaluating overall turnout while it is positive when using effective turnout. However, both differences across electoral districts are poorly significant. Accordingly, our findings are in line with the diverging conclusions from previous scholarly contributions based on a diversity set of countries, and more particularly with the Brazilian case where no statistically significant effect of on-site e-voting on turnout was found (Fujiwara, 2015).

Second, we report that Internet voting had a positive and significant impact non-resident citizens' voter turnout. Voter turnout using Internet voting increased as compared to previous elections and neighboring electoral districts. Compared to districts using ballot box voting, overall and effective turnout increased respectively by $13,09 \%$ and $12,12 \%$ in the district using Internet voting. This increase is even higher in the case of the presidential elections and in the case of female voters $(+15,31 \%$ and $+13,3 \%$ respectively). These findings are also in line with the literature as it confirms (and even surpasses) the positive effect of Internet voting on non-resident citizens observed in Switzerland (Germann, 2021) and in the USA (Fowler, 2020).

These findings call for further research on the impact of voting modalities on turnout across non-residents. First, we encourage researchers to duplicate their analyses by distinguishing between overall and effective turnout. Distinct electoral dynamics could be at play depending on the voting modality and this distinction could be particularly relevant when voting is compulsory or in the case of an election characterized by a large share of invalid votes. Second, our analyses indicated that the type of elections may also have a role in the interplay between e-voting and turnout. The comparison of the Ecuadorian elections with other cases would confirm if the positive impact of Internet voting is larger in the case of first-order elections, as opposed to other types of elections. Finally, the Ecuadorian case seems to indicate that gender is an important variable in the explanation of turnout: the positive impact of Internet voting on turnout is higher among female voters while the negative impact of DRE voting on turnout is higher among male voters. We therefore call for a closer look at gender dynamics in future voter surveys investigating the impact of e-voting on voter's behaviour.

\section{ACKNOWLEDGEMENT}

The authors thank the three anonymous reviewers for the useful comments.

\section{REFERENCES}

Allers, M.A. \& Kooreman, P. (2009). More evidence of the effects of voting technology on election outcomes. Public Choice, 139(1-2), 159-170.

Alvarez, M. R., and Hall, T.E. (2008). Electronic Elections: The Perils and Promises of Digital Democracy. Princeton: Princeton University Press.

Barnes, T.D. \& Rangel, G. (2018). Subnational Patterns of Participation: Compulsory Voting and the Conditional Impact of Institutional Design. Political Research Quarterly, 71(4): 826-841.

Bermúdez, A., Lafleur, J.M. \& Escrivá A. (2017). Contribuyendo a la democracia en países de origen: El voto externo de los migrantes andinos, América Latina Hoy, 76, pp. 35-54.

Bochsler, D. (2010). Can internet voting increase political participation? Remote electronic voting and turnout in the Estonian 2007 parliamentary elections. Paper prepared for presentation at the "Internet and Voting" conference. Fiesole (Italy), June 3-4.

Burgess, K. (2018). States or Parties? Emigrant Outreach and Transnational Engagement, International Political Science Review, 39(3), pp. 369-383.

Dandoy, R. (2014). The impact of e-voting on turnout: Insights from the Belgian case. Proceedings of the 2014 International Conference on eDemocracy \& eGovernment (ICEDEG). Quito (Ecuador), 29-37. 
Dandoy, R. \& Kernalegenn, T. (2021). Internet Voting from Abroad: Exploring turnout in the 2014 French consular elections, French Politics (published online).

Debnath, S., Kapoor, M. \& Ravi, S. (2017). The Impact of Electronic Voting Machines on Electoral Frauds, Democracy, and Development. Retrieved from https://ssrn.com/abstract=3041197

Dejaeghere, Y \& Vanhoutte, B. (2016). Virtuous villages and sinful cities? A spatial analysis into the effects of community characteristics on turnout and blank/invalid voting in local elections in Belgium 2006-2012. Acta Politica, 51, 80-101.

Desai, Z. \& Lee, A. (2019). Technology and protest: the political effects of electronic voting in India, Political Science Research and Methods (published online).

Fowler, A. (2020). Promises and perils of mobile voting. Election Law Journal, 19(3), 418-431.

Fujiwara, T. (2015). Voting Technology, Political Responsiveness, and Infant Health: Evidence from Brazil. Econometrica, 83(2), 423-464.

Germann, M. \& Serdült, U. (2017). Internet voting and turnout: Evidence from Switzerland. Electoral Studies, 47, 1-12.

Germann, M. (2020). Making votes count with internet voting. Political Behavior (published online).

Germann, M. (2021). Internet voting increases expatriate voter turnout. Government Information Quarterly (published online).

Goodman, N.J. \& Stokes, L.C. (2020). Reducing the cost of voting: An empirical evaluation of internet voting's effect on turnout. British Journal of Political Science, 50 (3), 1155-1167.

Petitpas, A., Jaquet, J.M. \& Sciarini, P. (2020). Does E-Voting matter for turnout, and to whom?. Electoral Studies (published online).

Ramírez, J. (2018), Estado, migración y derechos políticos: El voto de los ecuatorianos desde el extranjero, Foro Internacional, 4(234), pp. 755-804.

Spada, P., Mellon, J., Peixoto, T., \& Sjoberg, F.M. (2016). Effects of the internet on participation: Study of a public policy referendum in Brazil. Journal of Information Technology \& Politics, 13(3), 187-207.

Umpierrez de Reguero S. \& Dandoy, R. (2020). Extending the incumbency presence abroad. The case of MPAIS in Ecuadorian elections, in Kernalegenn T., van Haute E. (eds.), Political Parties Abroad. A New Arena for Party Politics, Routledge, London and New York, 115-132. 